\title{
Assessment of the quality of care in Maternity Waiting Homes (MWHs) in Mulanje District, Malawi
}

\section{Leticia Chimwemwe Suwedi-Kapesa, Alinane Linda Nyondo-Mipando}

University of Malawi, College of Medicine, School of Public Health and Family Medicine
Date Received: 20-March-2017

Revision Received: 08-Jan-2018

Date Accepted: 15-Jan-2018

Correspondence: Leticia

Chimwemwe Suwedi - Kapesa

(cletisuwedi@gmail.com)

ttps://dx.doi.org/10.4314/mmi.v30i2.10

\begin{abstract}
Aim
Abstract

Maternal Mortality Ratio (MMR)in Malawi remains high at 439 deaths per 100,000 live births, primarily due to limited access to skilled birth care. Although Malawi established Maternity Waiting Homes (MWHs) to improve access to skilled labour, the quality of care provided in the homes has received limited assessment. The aim of this study was to assess quality of care in the Maternity Waiting Homes in Mulanje, Malawi.

Methods

We conducted a descriptive qualitative study in three MWHs in Mulanje district, Malawi, from December 2015 to January 2016 . We conducted a non-participatory observation using a checklist, to assess the physical layout of the facilities, six face-to-face in-depth interviews (IDIs)with health providers and four focus group discussions (FGDs) with 27 pregnant women admitted for more than 48 hours in MWHs. We digitally recorded all FGDs and IDIs simultaneously transcribing and translating them verbatim into English. Data were analysed using thematic analysis.

Results

There were mixed perceptions towards the quality of care in the MWHs. Factors that were perceived to indicate higher quality included a quiet environment at the MWH and midwifery services. Lack of cooking spaces, lack of 24-hour nursing care, absence of food and recreation services and sleeping on the floor negatively affected perceptions of quality.

Conclusion

The study has shown that care provided in MWHs varied across facilities. Perceptions of the quality of care were not uniform and a lack of standards contributed to the differences. Efforts should be made to improve, sustain and standardize care in MWHs in order to improve perceptions of quality of care in MWHs.
\end{abstract}

\section{Introduction}

Maternal death is one of the major health problems in the world ${ }^{1-3}$, with $99 \%$ of maternal deaths occurring in developing countries and $57 \%$ in sub-Saharan Africa ${ }^{1-4}$. The Maternal Mortality Ratio for sub-Saharan Africa alone is 500 maternal deaths per 100,000 live births ${ }^{3}$, while in Malawi; MMR is at 439 deaths per 100,000 live births ${ }^{5,6}$. Although the MMR rates remain high in Sub-Saharan Africa, De Brouwere et al. contend that more than $80 \%$ of the maternal deaths are preventable through effective interventions, even in developing countries ${ }^{3}$. Lack of access to skilled birth care is the leading contributing factor to maternal deaths in developing countries ${ }^{1,3,4,7,8}$. One of the many interventions in place to improve access to skilled birth care is the establishment of Maternity Waiting Homes (MWHs) ${ }^{7}$. Access to skilled birth care is increased by accommodating pregnant women in nearby hospitals where emergency obstetric care is provided. MWHs are residential facilities within health institutions where women with high-risk pregnancies are admitted as they wait for their expected date of delivery ${ }^{9}$. Pregnant women with previous still births, operative delivery, high parity and high blood pressure, are some of the factors that define high-risk pregnancies. MWHs also cater for pregnant women who have poor access to skilled birth care from 35-40 weeks gestation ${ }^{7-11}$. Some countries developed their own MWH guidelines with admission protocols. For example, Mozambique includes geographical distance and high-risk pregnancy as criteria for admission into MWHs ${ }^{12}$.
An evaluation of MWHs published on the World Health Organization's (WHO) website showed that Malawi does not have MWH guidelines and that the admission protocol was not documented ${ }^{7}$. The evaluation highlighted that previously, Malawi used guardian shelters and postnatal wards to accommodate pregnant women close to the hospital instead of MWHs. Few women referred themselves to the shelters and others were recommended by health workers. The WHO evaluation stipulated minimum standards for MWHs which include three elements, health services, education and supportive services ${ }^{7}$.

Malawi adopted and officially implemented MWH interventions in 2012 under the presidential safe motherhood initiative $^{13}$. Currently, 18 districts in Malawi have MWHs, with Mulanje district pioneering the initiative in $2012^{13}$. The aim was to provide all women with regular checkups and education, especially those living far from the hospital. Despite the expansion of MWHs in Malawi, MWHs' specific guidelines and services management have not been documented $^{12,13}$. However, anecdotal reports show that, currently, most MWHs are using the Antenatal Care (ANC) guidelines. Although MWHs form one of the pillars of the presidential safe motherhood initiative and aim at linking pregnant women into the formal health system to improve maternal health ${ }^{13}$, there has been limited assessment on the quality of care provided in MWHs in Malawi. This study was guided by the Donabedian structure-process-outcome framework to assess quality of health care services in diverse 


\section{Data collection}

combining the Donabedian model and the WHO MWH's standards was that the Donabedian model helped to take on board all comprehensive variables that could lead to defining the quality of care in the MWHs, the structure, process and outcome, while the WHO's standards contextualize the assessment of quality of care using Donabedian aspects. Malawi does not have standards to guard the provision of services in the MWHs. Information on quality will assist in improving MWHs for them to meet their intended purposes of contributing to the improvement of maternal health and reduction of maternal deaths. In this study, we assessed
client and provider perspectives on quality of care in $\mathrm{MWH}$ in Mulanje, Malawi.

\section{Methods}

\section{Study design}

We conducted a qualitative descriptive study at Mulanje Mission Hospital, Mulanje District Hospital and Chonde Health Centre in Mulanje, Malawi, from December 2015 to January 2016 to assess client and provider perspectives on quality of care in MWHs. Of the 23 health facilities in
Mulanje, these health facilities were the only three facilities with a MWH at the time when this study was conducted.

\section{Study place and Sample size}

We purposively selected Mulanje district because it pioneered the establishment of $\mathrm{MWHs}^{14}$. We conducted a non-participatory observation of the physical layout of perceptions of hedh workers and pregnant woned on the perceptions of health workers and pregnant women on the face-to-face in-depth interviews (IDIs) with hellh pree six two at each hellth facility. We conveniently sampled and recruited 27 pregnant women who constituted four focus group discussions (FGDs). The pregnant women were those that were admitted for more than 48 hours in MWHs. At constitute an FGD18. We digitally recorded all FGDs to key infor an FGD key infornant ing Health workers assisted in identifying eligible pregnant women as per eligibility criteria. We verified the participant's demographic data as captured in their health passport book to achieve maximum variation in the selection of individuals with various characteristics to broaden responses ${ }^{19,20}$. We included both primigravidae and multigravidae who were of different ages and had spent varying lengths of time in MWHs in order to draw on various experiences and broaden the scope of the responses. In each of the two facilities, the FGDsearchers divided the women into two groups to constitute FGDs based on participants age to promote free expression MWH. One group had women aged 18 to 24 yeirs in MWe the other group had women aged 25 years and above. We roles and experiences in the MWHs. We included a nurse midwife and a guard from each MWH who had worked at their respect a six months because participants wo dect have the necessary skills and experience and would offer deeper insights into the quality of $\mathrm{care}^{18}$. We purposively included guard because they are a critical human resource stationed at
Data collection in the FGDs and IDIs followed pretested guides (Additional files 1 and 2: IDI and FGDs guide respectively). We collected data on perceptions on quality of care, descriptions and evaluations of care received, an challenges and recommendations regarding MWHs. W collected similar data from health care workers highlighting (Ad perspectives and how they provide the services (Additional file 3). Lach participant was interviewed once by rese trained by the researche on how to use the data collection tools and administer the FGDs lasted for $60-95$ m. lastes Data collectors

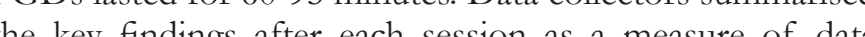
validation ${ }^{21}$. We stopped collecting data after data which was achieved when participants did not add any new information to the already collected data ${ }^{22}$.

We conducted non-participatory observations in all study sites using a checklist (Additional file 4: Non-participatory observation checklist). The checklst was developed to assess structural elements prescribed by the Donabedian theory. The checklist was developed from the minimum standards stated in the review of MWH published on the WHO website to assess whether or not certain structural aspects were present . Prior to data collection, the checklist was reviewed by the College of Medicine Research Ethic Committee (COMREC) and the supervisor's expert review. The researcher and one research assistant (both nurses) piloted data collection guides at South Lunzu Health Centre data credibility he con seur methodological triangulation ${ }^{18}$ by using different methods f data collection tools: IDIs, FGDs and non-partipars cervatio. We verise whether participants conticipatory matched with their intentions by repeating what had been discussed to validate the data ${ }^{18}$.

\section{Ethical approval}

Prior to study implementation, we sought ethical approval from COMREC on the protocol, consent documents and interview guides (COMREC -P.10/15/1818). We sought support and authorization from the Mulanje District Health facilities to conduct the study. We sought written informed consent from participants who were able to read and write and participants that were unable to read and write provided thumb prints on the consent forms in the presence of impartial witnesses. We used codes instead of participants' names to ensure confidentiality. Although the researcher and research assistants were nurse midwives, their identitic were concealed by not wearing uniforms, which helped to avoid compromising research findings. The researcher and the stuts were not employees from the studes.

\section{Data analysis}

We analysed our data manually following thematic analysis as suggested by Braunetal., which assistedin themeidentification and facilitated the organization and report patterns within data in detail . Our hemes were inductively and deductively developed from the data and the study objective, Donabedian and the WHO conceptual frameworks, respectively $7^{7,23,24}$
Prior to analysis, we transcribed recorded data, translate
If verbatim from Chichewa into English and read the Most women admitted to the MWHs were married $(\mathrm{N}=23$ ) transcripts multiple times which allowed for data immersion and 4 were single. 6 participants were able to read and write and familiarization. The two authors independently coded and most of the participants were unable to read and write one transcript. Different codes were discussed by the two $(\mathrm{N}=21)$. The participants' median age was 24 years, with authors and later, we agreed upon preliminary codes that were the age range of 18-29 years old. The median gravidity of used for the other transcripts. We also included other codes the women in the MWHs was 1, with the gravidity range that were not realized from the initial transcript as analysis progressed. We examined the codes and collated similar codes into categories to organize them under overarching themes ${ }^{24}$. We refined our themes by checking them against the recordings to ensure that they correctly represent the data and the conceptual frameworks that guided the study. We defined and explained the components of each theme. Codes that did not fit the established themes were presented separately to achieve an objective presentation of findings. We searched for inconsistent evidence and opposing details and named the themes by looking at the data that was taken on board, looking at the stories behind the themes and why the themes were important $t^{24}$

Results

Table 1: Demographic characteristics of focus group discussio participants

\begin{tabular}{|c|c|c|}
\hline Variable & $\mathrm{N}$ & $\%$ \\
\hline $\begin{array}{l}\text { Gravidity } \\
\text { Primigravidae } \\
\text { Multigravidae }\end{array}$ & $\begin{array}{l}15 \\
12\end{array}$ & $\begin{array}{l}56 \\
44\end{array}$ \\
\hline $\begin{array}{l}\text { Age } \\
18-24 \text { years } \\
25 \text { and above }\end{array}$ & $\begin{array}{l}14 \\
13\end{array}$ & $\begin{array}{l}52 \\
48\end{array}$ \\
\hline $\begin{array}{l}\text { Gestation in weeks } \\
32-35 \text { weeks } \\
36-39 \text { weeks } \\
40 \text { weeks }+\end{array}$ & $\begin{array}{l}2 \\
18 \\
7\end{array}$ & $\begin{array}{l}7 \\
67 \\
26\end{array}$ \\
\hline $\begin{array}{c}\text { Able to read and } \\
\text { write } \\
\text { Unable to read and } \\
\text { write }\end{array}$ & $\begin{array}{l}21 \\
6\end{array}$ & $\begin{array}{l}78 \\
22\end{array}$ \\
\hline $\begin{array}{l}\text { Duration of stay } \\
4 \text { days-3 weeks } \\
4 \text { weeks-8 weeks }\end{array}$ & $\begin{array}{l}25 \\
2\end{array}$ & $\begin{array}{l}93 \\
07\end{array}$ \\
\hline $\begin{array}{l}\text { Marital status } \\
\text { Single } \\
\text { Married }\end{array}$ & $\begin{array}{l}02 \\
25\end{array}$ & $\begin{array}{l}07 \\
93\end{array}$ \\
\hline $\begin{array}{l}\text { Number of } \\
\text { admission } \\
\text { First admission } \\
\text { Second admission } \\
\text { Median age: } 24 \text {. Age } \\
\text { range } 18-29 \\
\text { Median gravidity } 1 . \\
\text { Gravidity range } 1 \text {-3 } \\
\text { Median gestation } \\
\text { age: } 37 \text {. Gestation } \\
\text { age range } 34-40 \\
\text { weeks }\end{array}$ & $\begin{array}{l}25 \\
2\end{array}$ & $\begin{array}{l}93 \\
07\end{array}$ \\
\hline
\end{tabular}

The majority of the FGD participants were admitted for the first time in the MWHs $(\mathrm{N}=25)$ and or twice. The longest duration of stay in MWHs was 8 weeks and the least was 4 days, with a mean duration of 1.6 weeks.
政 37 weeks with the

Characteristics of pregnant participants in indepth interviews

The median age for the participants was 25 years with the age range of $19-30$ years. 4 of the participants were married and only 2 were single. There were equal numbers of pringavida and nulugravidae $(\mathrm{N}=3)$. Among the pregnant on 4 age more than 4 weeks. 4 participants had stayed for less than 3 weeks, wille 2 participants had stayed in the MWHs for betwe

\section{Characteristics of health workers}

The health workers included three nurse midwife technician and three guards. The nurses' highest level of qualificatio was a diploma in nursing and midwifery whilst the guards highest level of education was the Malawi Junior Certificate of Education (JCE). The duration of employment for the health workers ranged from 6 months to 6 years

\section{Participants' satisfaction with quality of care in} maternity waiting homes

The major themes that emerged under the theme of 'quality of care' were: (a) high quality of care in the MWHs, and (b) low mixed perceptions of the quality of care in MiVHs. A list of

\begin{tabular}{|l|l|}
\hline Emerging themes & Subthemes \\
\hline 1. High quality of care in MWH & $\begin{array}{l}\text { 1. Quiet environment } \\
\text { 2.Midwifery services } \\
\text { a. Close monitoring of pregnant } \\
\text { women } \\
\text { b. Referral services }\end{array}$ \\
\hline 2. Low quality of care in MWH & $\begin{array}{l}\text { 1. Nutrition support } \\
\text { a. Lack of cooking space } \\
\text { b. Lack of food } \\
\text { 2. Lack of 24-hour nursing care } \\
\text { a. Challenges during labour } \\
\text { b. Human resource } \\
\text { i. Health workers' attitude } \\
\text { c. Security at night } \\
\text { d. Inadequate material } \\
\text { resources } \\
\text { i. Documentation supplies and } \\
\text { drugs } \\
\text { 3. Recreation services } \\
\text { a. Recreation supplies } \\
\text { 4. Infrastructure } \\
\text { a. Lack of beds } \\
\text { b. Poor amenities } \\
\text { i. Water supply } \\
\text { ii. Washroom lighting }\end{array}$ \\
\hline
\end{tabular}

a) Good quality of care in maternity waiting homes Participants who were satisfied with the quality of care in the MWHs described the care as adequate. Some stated that 
cate they received met their expectations because the health care workers addressed the problems that led to their admission. In some instances, participants were satisfied sound scanning.

"I just thank them that the care that we are receiving here is adequate. For example, during the night some women do not have food or relish. Mulanje District Hospital)

II am happy with the care that I am receiving because after assessment, if they think that something is not okay they ask. the pregnant woman to go for scanning." (PW IDI, Mulanje District Hospital) The health care workers' gratitude corroborated the participant's expression of satisfaction as follow:

"T feel happy if women have been assisted nicely... [when we meet] they would call me and show me the baby that was born ... that makes me alth Centre)

Participants were also pleased with the accommodation.

"This place is good and free. Allows fresh air and a person can do whatever she please.

\section{b) Low quality of care in $M W H s$}

In all the study sites, there were participants dissatisfie with the services; some expressed boredom, shared time in managing their homes and others expressed unhappines
with staying in the MWHs.

"We are even tired here... There is notbing that makes me happy bere.”(PW, FGD Mulanje District Hospital MWH)

"There is notbing interesting... In our bome we even sleep on beds and we have the mosquito nets." (PW FGD Mulanje Mission Hospital $\mathrm{MWH}$ )

"Our busbands are forced to stay home and look after the bouse and the ther kids at the same time they have to bring food for us their wives her so it is not simple." (PW, IDI Chonde Health Centre)

\section{Factors that influence quality of care in maternal} waiting homes

Several factors influenced the quality of care in the MWHs, such as resources for quality care and storage of information.

\section{Drugs and other hospital supplies}

Health care workers in all the study sites reported that most of the time, they are not supplied with all the necessary materials needed for the MWHs, for example iron supplements.

"The resources that we require include gloves and ferrous sulphate [iron supplements. However we have stayed close to two months without
baving the iron supplements in stock." (SP, IDI Chonde Health baving the it
Centre)

Amenities: Water supply, wash rooms, lighting

Participants at Mulanje District Hospital MWH reported they do not always have a water supply within the facility a If the water bill is paid.

"Most of the time we do not have the water supply, we do go down [to] (PW, FGD Mulanje District Hospital MWH)

Participants from Mulanje District Hospital MWH also reported that they do not have adequate lighting in the washroom, which makes it difficult to use during the night. Participants at Mulanje Mission Hospital MWH reported that they have washrooms, but they are inadequate for the number of clients. At Chonde Health Centre MWH, participants said that the washrooms are not hygienic.

We have only one batbroom and one toilet to cater for about 30 plus people who are waiting inside, so it is very difficult for us to use at the same time..." (PW FGD Mulanje Mission Hospital MWH)

\section{Transportation resources} is an ambulance for use when clients are referred to othe locations. Participants at Mulanje District Hospital MWH mentioned that there are no wheelchairs or trolleys, making it difficult to go to the labour ward.

"Ever since I came here, I have never seen a woman taken on the wheelchair." (PW, FGD Mulanje District Hospital MWH)

Participants at Mulanje District Hospital MWH reported that during the night, when they are going to the labour ward, pregnant women use personal phones as a torch, and the guards do not have the necessary materials.

...If one of the women on the group has a phone, then we light the torch..." (PW, IDI Mulanje District Hospital MWH)

\section{Challenges during Labour}

Participants highlighted challenges such as giving birth in the in labour.

"Some women do deliver in the corridors ... they are also told that the should go move around and if you happen to give birth in the corridor they shout at you." (PW Mulanje District Hospital MWH)

\section{Poor documentation}

Health providers at Chonde Health Centre MWH and Mulanje District Hospital MWH reported that they do not have files or registers for record keeping, which limits the information and statistics on their clients.

"We used to have admission books ... but because of shortage of resounces we do not write anywhbere the information about the women. (SP IDI Mulanje District Hospital MWH)

"It is impossible to track the pregnant women who were in the $M W H s$. . "Stationery, we do not have. Even BP macbine, we do not have."(SP IDI, Mulanje District Hospital)

"It is impossible to track the pregnant women who were in the MWW the hospital, we use pit latrines and sometimes we even bathe there.

Participants at Chonde Health Centre reported that there corridor, and midwives' delays in attending pregnant women
Participants and health providers in all study sites reported lack of nurses to provide care to pregnant women around the clock. Participants at Chonde Health Centre MWH reported that they have a schedule for nurses; not only do nurses rarely adhere to the schedule, but they are understaffed as well

"Yes the women stay with the guard. There are no midwives in the MWHs." (SP IDI Mulanje Mission Hospital MWH)

\section{Security within MWHs}

Participants and health workers at Mulanje District Hospita MWH and Chonde Health Centre MWH stated that participants would report to the labour ward at night without the escort of security guards. At Chonde Health Centre, male guards were not comfortable to look after pregnant women because it is culturally inappropriate. As a result, MWHs were left unguarded leading to loss of resources through theft. "I wish we had two guards ... We feel scared, but we still go because we travel in large groups. '(PW FGD Mulanje District Hospital

Participants in all centers complained of inadequate human and material resources. Participants reported that MWH lacked human resources that could support with recreational activities and they lacked materials that they could use. providers requested pregnant women do their work for them. Participants at Mulanje Mission MWH complained that the home was not spacious; some pregnant women had to sleep on the floor. At Chonde Health Centre MWH, pregnant women reported sleeping on the floor, even though beds were available because they were advised not to use them. Similarly, at Mulanje District Hospital MWH, some women slept on the floor because there was no bedding and sleeping

The floor because there was no bedding and sleeping
Table 3: Presentation of the non-participatory observation results from all the study sites
\begin{tabular}{|l|l|l|l|l|}
\hline Variables & Mulanje MWH & Chonde MWH & Mulanje Mission & Comments \\
\hline Infrastructure & $\begin{array}{l}\text { New and strong } \\
\text { building }\end{array}$ & $\begin{array}{l}\text { One building } \\
\text { with no rooms }\end{array}$ & $\begin{array}{l}3 \text { rooms allocated } \\
\text { as MWHs at the } \\
\text { guardian shelter }\end{array}$ & $\begin{array}{l}\text {-Guardians are not permitted to stay } \\
\text { at Mulanje MWH } \\
\text {-A Mulanje Mission most pregnant } \\
\text { women were found at the waiting } \\
\text { homes outside. The rooms were } \\
\text { closed as they were being fumi } \\
\text { gated. } \\
- \text { Mhe Anti Natal Ward (ANW) at } \\
\text { Mulanje mission had few beds with } \\
\text { t toilet and bathroom, torn bed nets } \\
\text { and was also used as a MWH }\end{array}$ \\
\hline & $\begin{array}{l}\text { Four bays } \\
\text { each with } \\
\text { eight beds }\end{array}$ & $\begin{array}{l}\text { No beds; } \\
\text { no mattresses }\end{array}$ & 10 cemented beds & \\
\hline & $\begin{array}{l}\text { Bed nets } \\
\text { available }\end{array}$ & $\begin{array}{l}\text { Bed nets not } \\
\text { available }\end{array}$ & Bed nets available & \\
\hline & No bedding & No bedding & No bedding & \\
\hline & $\begin{array}{l}\text { Electricity } \\
\text { available }\end{array}$ & $\begin{array}{l}\text { Electricity } \\
\text { available }\end{array}$ & Electricity available & \\
\hline
\end{tabular}

on the mattress without bed sheets made the pregnant of which quality was captured in the process ${ }^{25-28}$. Had we women feel excessively hot. Observations of the physical ayout of the MWHs are elaborated in Table 3 .

w We are sleeping on the beds, but if there are a lot of women others been incorporated; however some ideas may be abstract. Ou

Participants from Chonde Health Centre MWH and Mulanje Mission Hospital MWH reported that they were not offered food, while participants from Mulanje District Hospital MWH expressed concern over the poor quality and inadequacy of the food provided.

The absence of a kitchen creates a challenge for the ceported to use the hospital kitchen instead of the MWHs although it exists. Due to long distance between the MWH

"We cannot prepare food at the MWH because the available kitchen is not functioning." (PW FGD Mulanje District Hospital) wer provided ther participants do not use nets because they do not sleep on the bed and some nets are stolen.

main finding of our study was that, some pregnant women and health workers were satisfied with the quality of care in the MWHs, whilst others were dissatisfied. Our findings hould be interpreted in the context of the Donabedian theory and the minimum standards for the MWH as laid out by the $\mathrm{WHO}^{7,23}$. Most studies on MWHs conducted outside Malawi did not focus on assessing the perception of quality Furthermore, participants stated that other health care workers expressed a bad attitude towards the clients. Some sleep on the floor." (PW IDI Mulanje Mission MWI

on participants at Mulanje District Hospital. Participants titchen becruse the MWH kitchen was not declared open 

Pregnant women who meet the admission criteria to the MWHs ${ }^{10,11,34}$. Nevertheless, MWHs should accommodate other pregnant women, as there is a potential for a pregnancy pre to turn into a high risk pregnancy, with a priority placed on dissatisfied with the quality of care in the MWHs. A women with actual risk factors?

study by Sialubanje et a $\mathbf{l}^{30}$ in rural Zambia reported that The use of the postnatal ward as a MWH may be expressed as

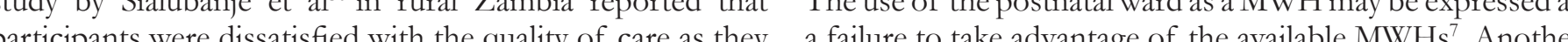
had problems with sleeping space, cooking space and the reason that could partially explain the use of postnatal war availability of water; this influences the quality of care in for the purpose of MWH could be staff shortages. This is the $\mathrm{MWH}^{30}$. These findings highlight the importance of evident in the review of MWHs experience by WHO in 1996 understanding Abraham Maslow's hierarchy of needs when which indicated that Malawian postnatal wards, guardian providing MWH services to pregnant women, which places shelters and antenatal wards were used to accommodate safety and physiological aspects as fundamental needs of a high risk pregnant women? ${ }^{7}$. In addition, the findings sugges human being ${ }^{30,3}$.

In our study, nutrition was one of the factors that led to dissatisfaction with the quality of care, which is similar to the study findings from Tanzania, Democratic Republic of Congo and Ghana 27,32. In Tanzania, MWHs provided poo quality food and in small quantities? As with the participants from our study, women in Tanzania purchased and prepared like Cuba, Lesotho and Cambodia which provide food to pregnant women $8,1,11$. Cognizant of the unavailability of adequate food in MWHs in Malawi, we advocate for constan education for the pregnant women on the nutritious food groups and birth preparedness in the event they are admitted weeks prior to their expected date of delivery.

Our findings on the security of pregnant women in MWHs concur with studies in Zambia and Ghana where women were concerned with medical safety, transportation to the hospital and security ${ }^{7,27,32}$. In Ghana, the location of the MWH was
far from the hospital and pregnant women were raty far from the hospital and pregnant women were rarel when labour started, especially during the night ${ }^{33}$. Similarly, in our study, women in labour have to walk to the hospital on their own despite having guards available. This is especially problematic at night; clients use a phone as a source of light along the poorly lit footpath. This is inconsistent with the WHO's recommendations that MWHs should have health providers to initiate the transfer of pregnant women to the hospital, and in the case where there is limited staff, guard as they are referred to the hospital

However, the WHO's recommendations state that this kind of arrangement only overcomes geographical barriers and pregnant women still have a risk on childbirth problems Based on the WHO's MWH recommendation, our finding access to assisted delivery by skilled labour. Furtheman's the WHO states that there should be an alarm system, transportation arrangements and communication between the MWHs and the hospital to ensure that referral to the hospital is on time and efficient ${ }^{7}$. Our findinos show that the ecommendation of efficient and timely referral was not met and preonant women still encounter challenges in accessing skilled birth care, despite admission in the MWH.

\section{Study limitations}

Our study had some limitations such as use of heath car workers as research assistants who could have their own biases. However, researchers professions and identities were concealed and were not employed in Mulanje District. Our study was limited to Mulanje District and only focused on women that used the MWH, hence results may be limited in application. Nonetheless, our study brings forward the state 作 first district where MWHs were formerly launched.

\section{Conclusion}

The key finding of our study showed that some participants were satisfied with the quality of care in the MWHs, while quality of care in this study were a good environment at the MWH and the midwifery were a good environment at the absence of food, lack of nursing care around the clock, lack of recreation services and a lack of available beds negatively affected perception of quality. The health workers perceived the quality of care to be compromised because there was not enough staff to provide adequate nursing care around the clock and a lack of material resources. The services provide in MWHs include educational services, accommodation and midwifery services. The challenges in MWHs were inadequate human and material resources and compromised security. The unique finding of our study is the lack of guidelines for MWHs which would create variations in the provision of care in the MWHs within a district.

\section{Acknowledgements}

This study was partially funded by Eastern Produce Malaw Limited. We are grateful to the pregnant women and healt care workers who participated in the study. We acknowledge the support rendered by the following research assistants: Chimwemwe Misanjo Martin Kapesa

\section{Authors' Contributions}

LCSK planned the study, developed study methods, developed interview guides and conducted observations, FGDs and indepth interviews, developed an analysis plan, analysed the data and drafted the manuscript. ALNM supervised the planning, development of the methods, analysis plan, and data analysis and contributed and supervised the manuscrip writing. All authors read and approved the final manuscript.

\section{References}

1. WHO, UNICEF, UNFPA, the World Bank, United Nations Populatio Division. Trends in Maternal Mortality 1990 to 2013 [Internet]
2016 [cited $2016 \mathrm{Apr} 25$ ]. Available from: http://apps.whoint/iris bitstream/10665/112682/2/19789241507226 eng.pdf April 2016

2. Prata N, Passano P, Sreenivas A, Gerdts CE. Maternal mortality in developing countries: challenges in scaling-up priority interventions. Women's Health Lond Engl. 2010 Mar; 6(2):311-27.doi:10.2217/

3. Brouwere V, Zinnen V, Delvaux T. How to conduct Maternal Deat 2014 [cited 2016 Apr 25]. Available from: http://www figo org/sites default/files/uploads/project-publications/LOGIC/Vfinaledited $\% 20$ MDR\%20guidelines\%20final\%202014.pdf

4. WHO, UNICEF, UNFPA, World Bank. Trends in maternal mortality: 990to 2008 [Internet]. [Cited 2016 Apr 25]. Available from: https: www.unfpa.org/sites/default/files/pub-pdf/trends_matmortality90-08.

WHO, UNICEF. Accountability for maternal, newborn and child survival the 2013 update [Internet]. [Cited 2016 Apr 25]. Available news/count complete small.pdf

6. National statistical office (NSO), ICF, MACRO. Malawi Demographic and Health Survey [Internet]. 2010 [cited 2016 Apr 26]. Available from: hurvey-preliminary-reporththtm/

7. World Health Organisation. WHO maternity waiting homes: review of experiences [Internet]. 1996 [cited 2016 Apr 20]. Available from: http://www.who.int/repro
perinatal_health/MSM_96 21/en

8. Wild K, Barclay L, Kelly P, Martins N. The tyranny of distance maternity waiting homes and access to birthing facilities in rural TimoLeste. Bull World Health Organ. 2012 Feb 1:90(2):97-103.

9. Wild KJ. Maternity waiting homes and the Shaping of Matern Health Policy in Timor-Leste. 2008; 16(31):83-92.

10. Satti H, Mclaughlin M, Seung K. The role of Maternity Waitin in in Lesotho [Internet]. 2013 [cited 2016 Apr 25]. Available from: http: parthealth.3cdn.net/9bf175c874bdaa9a1d_h8m62u9hy.pd

11. Kingdom of Cambodia. National guide line on waiting hom 2010 [cited 2016 Apr 26]. Available from: http://parthealth.3cd. net/9bf175c874bdaa9ald_h8m62u9hy.pdf

12. Ruiz IZ. Effectiveness assessment of maternity waiting homes in increasing coverage of institutional deliveries using geographical information systems in six districts of Cabodelgado Province [Mozambique] [Internet]. [Cited 2016 Apr 25]. Available from: http:/ www.rmchsa.org/wp-content/uploads/2013/11/MWH_Effectiveness

13. Butrick E, Smith D, Beyeler N, Montagu D. pshi-strategies-toincrease-health-facility-deliveries: Three case studies, Global health, http://globalhealthsciences.ucsf.edu/sites/default/files/content/ghg -strategies-to-increase-health-facility-deliveries.pdf 4. Donabedian A. The quality of care. How can it be assessed? JAMA.
1988 Sep 23; 260(12):1743-8.

5. Cooper J, Lewis R, Urquhart C. Using participant or non-participant observation to determine information behaviour - download. Available \&rep=rep1\&type=pdf. (Accessed: 6th February 2017)

6. Liu F, Maitlis S. Methods of research - non-participant observation

17. Parke J. Participant and non-participant observation in gambling - volume-1-issue-1-parke-grifftiths.pdf. Available at: https://www. me-1-issue-1bruary 2017)

18.Mack N, Wood song K, Guest G. Qualitative research methods: A data collector's field guide [Internet]. FHI 360. [Cited 2016 Apr 26]. (a) methods-data-collector

19. Patton M. (1990) Qualitative

methods (pp.

. Green C, Palinkas 1, Horwitz S, Wisdom ND. Purposeful sampling for qualitative data collection and analysis in mixed method implementation research [Internet]. [Cited 2016 Jun 28]. Available b00e-cf3425b39a5c/OTPP_PTPP\%20536\%200NL/Articles/Palinkas Sampling_AdmPolicyMentHealth_2013.pdf

21. Cohen D, Crabtree B. RWJF - Qualitative research guidelines Available from: http://www.qualres.org/HomeFocu-3647.html research. 20(9):1408-16.

23. Donnabedian A An introdection to qulity asurence in heath 2016 Apr 26]. Available from: https://global.oup.com/academic product/an-introduction-to-quality-assurance-in-health-care9780195158090?cc=us\&lang=en\&

4. Braun V, Clarke V. Using thematic analysis in psychology. Qual Res Psychol. 2006 Jan 1; 3(2):77-101.

25. Sialubanje C, Massar K, Van der Pijl MSG, Kirch EM, Hamer DH, Ruiter RAC. Improving access to skilled facility-based delivery of maternity waiting homes in rural Zambia. Reprod Health. 2015; 12:61.

26. Ruiz M, Marieke G, Berdichevsky K. Barriers to the use of maternity waiting homes in indigenous regions of Guatemala: A Study of users'
and community members' Perceptions | Traction Project [Internet]. 2012 [cited 2016 Apr 25]. Available from: http://www.tractionproject.org/ barriers-use-maternity-waiting

27. Van Lonkhuijen L, Stekelenburg J, Van Roosmalen J. Maternity waiting facilities for improving maternal and neonat Rev. 2009; (3):CD006759.

28. Mramba L, Nassir F, Ondieki C, Kaimanga D. Reasons for low utilization of a maternity waiting home in rural Kenya - International
Journal of Gynecology and Obstetrics [Internet]. [Cited 2016 May 5] Available from: http://www.ijgo.org/article/S0020-7292 [09]00524-4/ abstract

9. Srivastava A, Avan BI, Rajbangshi P, Bhattacharyya S. Determinants from developing countries. BMC Pregnancy Childbirth. 2015; 15:97 30. Sialubanje C, Massar K, Van der Pijl MSG, Kirch EM, Hamer 
services: Women's beliefs on facilitators and barriers to the utilisation of maternity waiting homes in rural Zambia. Reprod Health. 2015; 12:61.

31. Maslow AK. Maslow's hierarchy of needs pyramid - Maslow's hierarchy_of_needs.pdf [Internet]. [Cited 2016 Jun 6]. Available from: http://accountability.spps.org/uploads/maslow_s_hierarchy_of_needs. pdf

32. Options Consultancy Services Ltd, Partnership management, Evaluation \& learning (PMEL). 2015 Literature review of maternity waiting homes. London: PMEL._online_1.pdf [Internet]. [Cited 2016 May 4]. Available from: http://www.mamaye.org.sl/sites/default/files/
evidence/PMEL_2015_Literature\%20review\%20of\%20maternity $\% 20$ waiting\%20homes_online_1.pdf

33. Wilson J, Collison AH, Richardson D, Kwofie G, Senah K. The maternity waiting home concept: the Nsawam, Ghana experience International Journal of Gynecology and Obstetrics [Internet]. 1997 [cited 2016 Apr 26]. Available from: http://www.ijgo.org/article/S00207292 [97]00162-8/abstract

34. Gorry C. Cuban Maternity Homes: A Model to Address At-Risk Pregnancy. MEDICC Rev. 2011; 13(3):12-5. 